\title{
Correlation of Serum Amylase and Peritoneal Fluid Amylase with, Perforated Peptic Ulcer and its Complications
}

\author{
Ramneik Manglik ${ }^{1}$, Venu Gopal K.² \\ ${ }^{1}$ Assistant Professor, Department of General Surgery, K. S. Hegde Medical Academy (KSHEMA), Mangalore, Karnataka, India. \\ ${ }^{2}$ Professor, Department of General Surgery, Kempegowda Institute of Medical Sciences, Bangalore, Karnataka, India.
}

\section{ABSTRACT}

\section{BACKGROUND}

Despite a declining incidence of peptic ulcer disease, the incidence of peptic ulcer disease complicated by either bleeding or perforation has remained constant or in fact even increased. The patient, who may have a history of peptic ulceration, develops sudden onset severe generalized abdominal pain due to the irritant effect of gastric acid on the peritoneum. Treatment still consists of primary closure of the perforation by a single stitch suture and a convenient tag of adjacent omentum on top of this. PPU still remains a dangerous surgical condition, associated with high morbidity and mortality. We wanted to study the symptoms, signs, mode of presentation and post-operative complications in perforated peptic ulcer. We also wanted to study the serum amylase and peritoneal fluid amylase levels and their correlation with complications like haemodynamic status, other blood investigations also to co-relate the same with duration of perforation, amount of spillage, size, site and number of perforations.

\section{METHODS}

This was a prospective study conducted on 30 patients who were admitted with hollow viscus perforation diagnosed as peptic ulcer perforation intra-operatively. Thorough history was taken, and clinical examination was done. Mode of presentation with complications and post-operative complications were noted and were correlated with size, duration of perforation and also amount of fluid in peritoneal cavity. These parameters were correlated with serum and peritoneal fluid amylase levels along with other blood investigations. A follow up examination was conducted for a minimum period of 6 months.

\section{RESULTS}

There was a significant direct correlation between serum amylase levels and duration of perforation $(r=0.41, p=0.03)$, size of perforation $(r=0.4, p=0.03)$ and amount of spillage $(r=0.66, p<0.001) .6$ patients had serum amylase levels of more than 300,4 presented with shock, 5 developed post op complication and 1 died.

\section{CONCLUSION}

Peptic ulcer perforation is a serious abdominal condition and mortality and morbidity increases as serum amylase and peritoneal fluid level amylase increases. Hence serum amylase and peritoneal fluid amylase can be used as indirect predictors for morbidity and mortality in cases of peptic ulcer perforation.

\section{KEY WORDS}

Peptic Ulcer Perforation, Serum Amylase, Peritoneal Fluid Amylase, Haemodynamic Status
Corresponding Author: Dr. Ramneik Manglik, Assistant Professor, Department of General Surgery, K. S. Hegde Medical Academy, (KSHEMA), Mangalore-575018, Karnataka, India. E-mail: ramneikmanglik@gmail.com

DOI: $10.14260 / \mathrm{jemds} / 2019 / 629$

Financial or Other Competing Interests: None.

How to Cite This Article: Manglik R, Gopal VK. Correlation of serum amylase and peritoneal fluid amylase with, perforated peptic ulcer and its complications. J. Evolution Med. Dent. Sci. 2019;8(38):2897-2901, DOI: $10.14260 / \mathrm{jemds} / 2019 / 629$

Submission 15-06-2019,

Peer Review 08-09-2019,

Acceptance 14-09-2019,

Published 23-09-2019. 


\section{BACKGROUND}

The common complications of peptic ulcer are perforation, bleeding and stenosis.[1] Once relatively common across all age groups, in the 21st century peptic ulcer disease is predominantly a disease of the elderly. Patients presenting with complications of peptic ulcer disease are most commonly in the seventh and eighth decades of life and there is a male predominance, with roughly 1.5 times as many cases in men than women.

Duodenal ulcer is more common than gastric ulcer, although the largest decreases in ulcer incidence have been seen in duodenal ulcer. Despite a declining incidence overall of peptic ulcer disease, the incidence of peptic ulcer disease complicated by either bleeding or perforation has remained constant or in fact even increased.[2]

The classic presentation of perforated duodenal ulcer is instantly recognizable. The patient, who may or may not have a history of peptic ulcer disease, develops sudden onset pain abdomen which spreads to generalized abdomen due to the irritant effect of gastric acid and bile on the peritoneum. ${ }^{[3]}$

Patients has tachycardia, hypotension, tachypnoea, peripheries are generally cold, dehydration, abdomen guarding and rigidity, rebound tender or percussion tenderness, obliterated liver dullness with absent bowel sounds. If not resuscitated properly patient quickly sinks into tertiary stage of peritonitis that is profound shock, Acidosis, hypothermia, altered sensorium,

Death following which is imminent.

An erect plain chest radiograph will reveal free gas under the right dome of diaphragm in an excess of 50 per cent of cases with perforated peptic ulcer but CT scan imaging is more accurate. Patients with hypotension should have Left lateral decubitus $\mathrm{X}$ ray done. All patients should have serum amylase performed, as distinguishing between peptic ulcer, perforation and pancreatitis can be difficult clinically.[4,5]

Measuring the serum amylase, however, may not remove the diagnostic difficulty. It can be elevated following perforation of a peptic ulcer, Intestinal obstruction, Bowel gangrene, Acute Calculous cholecystitis, ruptured ectopic pregnancy, although, fortunately, the levels are not usually as high as the levels commonly seen in acute pancreatitis.

Surgery for PPU still is a subject of debate. Reviewing different policies regarding for instance the indication for conservative treatment, sense or no sense of drains, the need for omentoplasty or not, performing the procedure laparoscopically and the need for definitive ulcer surgery like vagotomy with or without ulcer excision, might contribute to establishing consensus.[6]

\section{METHODS}

A prospective study was conducted in one of the private medical colleges of Bangalore after obtaining institutional ethical committee clearance. During the study period number of cases admitted and selected for the study were 30 . The details of these cases were organized in master chart for the convenience of analysis and presentation. The provisional diagnosis was made on the basis of clinical examination, investigations like $\mathrm{X}$ rays, ultrasound or $\mathrm{CT}$ if required, confirmation of diagnosis was done on laparotomy. A thorough examination was done at the time of presentation and detailed history was taken when patient's condition was stable. Preoperatively patients were hydrated with Normal saline and ringer lactate, hydration at $15-20 \mathrm{ml} / \mathrm{kg}$ was rushed and maintenance was given at $150 \mathrm{ml} / \mathrm{hr}$, Ryle's tube and Foley's catheter were inserted and urine output was monitored.

Broad spectrum antibiotic was started like piperacillin Tazobactam along with Metronidazole cover, proton pump inhibitor like pantoprazole were started $12^{\text {th }}$ hourly. Abdomen was accessed through vertical midline incision, and after sucking the contaminated fluid, a search for perforation was made.

First in supra colic compartment in sequential manner, then infracolic compartment, after that a copious lavage with warm saline was given.

Right sub phrenic space, left sub phrenic space, inter bowel spaces, right and left paracolic gutter and pelvis were thoroughly irrigated, till fluid became clear. In all cases closure of perforation was done using Pedicle omental patch using Vicryl 2-0 on round body needle. No attempts were made to suture the perforation also no attempts were made to do Vagotomy, in suspected cases where mass was palpable, a wedge biopsy of edge of perforation was taken. Abdomen was closed after putting drains. One drain in pelvis and another in Morrison's pouch near perforation, feeding jejunostomy was added if perforation was bigger than $2 \mathrm{~cm}$.

Unstable patients were shifted to ICU and inotropes were started if required. In our study we used noradrenaline infusion 2 ampules in $45 \mathrm{ml}$ Normal Saline at $4-8 \mathrm{ml}$ per hour, along with acidosis correction in the form of bicarbonate infusion, Patients who were not fit for anaesthesia were managed by putting abdominal drains under local anaesthesia and following resuscitation and stabilisation were taken up for surgery.

Post operatively vitals and urine output were monitored hourly, midline wound was inspected on POD3, DVT prophylaxis was given in form of crepe bandages, chest physiotherapy and spirometry were started on POD1, drains were inspected daily for bile leak. Pelvic drains were removed on POD 4 and Morrison's pouch drains were removed on POD 6 after allowing patient oral liquids, in our study we did not do contrast study, however in Doubtful cases oral methylene blue was given to the patient.

During follow up period patients were put on Helicobacter pylori eradication regimen for 2 weeks, followed by proton pump inhibitor for 6 months.

\section{Inclusion Criteria}

Admitted cases of perforation, diagnosed intra-operatively as gastroduodenal perforation.

\section{Exclusion Criteria}

- Perforation other than peptic ulcer perforation.

- Perforation secondary to blunt trauma of the abdomen.

- Perforation secondary to penetrating trauma of the abdomen.

- Peptic ulcer perforation patients who are managed conservatively. 


\section{Statistical Analysis}

Data Analysis: Data were analysed using SPSS 16. Frequencies and means were determined for both the independent and dependent variables. Bivariate relationships were determined using Pearson's, Chi square analysis between Serum amylase and other dependent variables. $\mathrm{P}$ value $<0.05$ was taken as significant in this study.

\section{RESULTS}

The mean age of the study sample was $47.3 \pm 17.5$ years. The maximum number of cases were of old age group that is 60 70 years, 12 cases. Most of the cases were males, that is 28 out of 30 (93\%) showing male predominance of the disease.

\begin{tabular}{|c|c|c|}
\hline Signs and Symptoms & No. of Cases & Percentage \\
\hline Pain Abdomen & 30 & $100 \%$ \\
\hline Vomiting & 18 & $60 \%$ \\
\hline Abd. Distention & 14 & $46.7 \%$ \\
\hline Tenderness & 30 & $100 \%$ \\
\hline Rigidity & 11 & $36.7 \%$ \\
\hline \multicolumn{2}{|c|}{ Table 1. Distribution of Signs and Symptoms } \\
\hline
\end{tabular}

All cases had history of pain abdomen (100\%), $60 \%$ had vomiting. Among signs all cases had tenderness $(100 \%)$ and $36 \%$ had rigidity. Hence pain abdomen with generalized tenderness should be worked up to rule out hollow viscus perforation.

\begin{tabular}{|c|c|c|c|c|c|}
\hline $\begin{array}{c}\text { Duration of } \\
\text { Perforation }\end{array}$ & Cases & Tachycardia & Shock & S. Amylase & P. F. Amylase \\
\hline 0-6 Hrs. & 6 & 2 & 0 & 91 & 424 \\
\hline 6-12 Hrs. & 4 & 3 & 0 & 209 & 2218 \\
\hline $12-24$ Hrs. & 17 & 14 & 4 & 201 & 2893 \\
\hline$>24$ Hrs. & 3 & 3 & 3 & 319 & 6075 \\
\hline Table 2. Correlation of Duration of Perforation with Sepsis and \\
Serum Amylase and Peritoneal Fluid Amylase \\
\hline
\end{tabular}
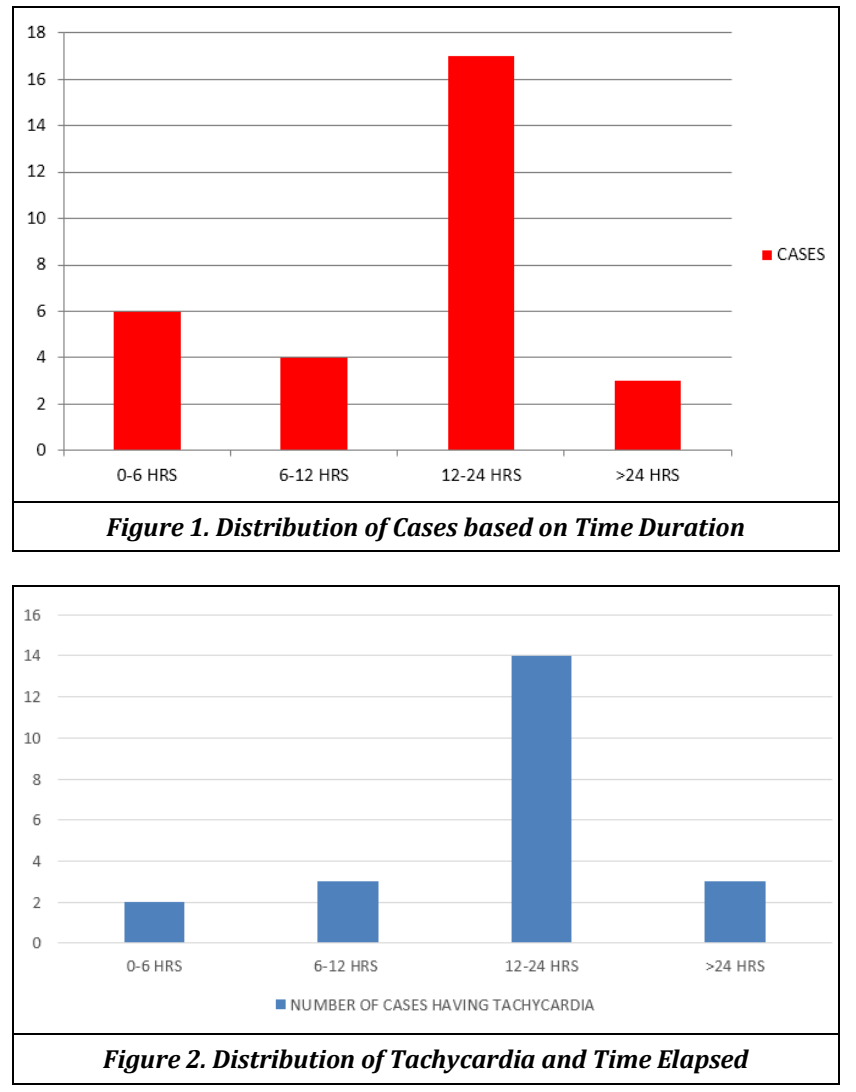
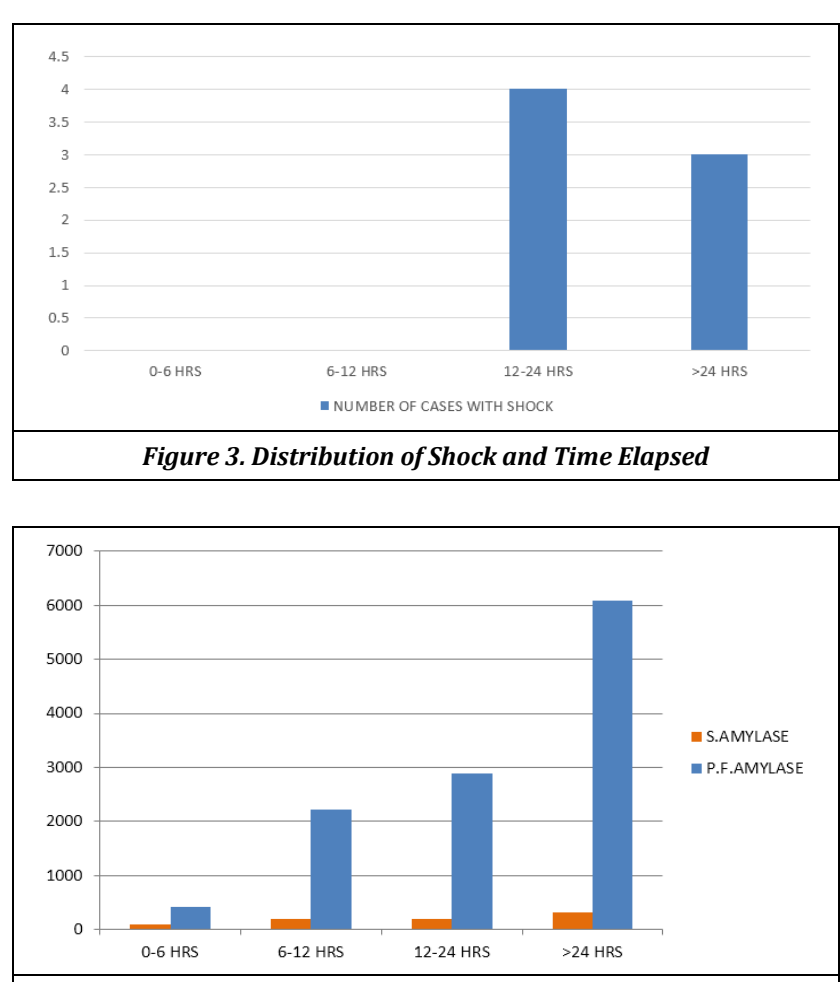

Figure 4. Correlation of Duration of Perforation with Serum Amylase and Peritoneal Fluid Amylase

In our study as the duration of perforation increased the complication like tachycardia and septic shock increased, in cases presenting within $12-24 \mathrm{hrs} 82 \%$ had tachycardia and $23 \%$ had shock and average serum amylase value was 201 , in cases presenting more than 24 hrs $100 \%$ cases had tachycardia and shock also serum amylase value was high that is 319 .

\begin{tabular}{|c|c|c|c|c|c|}
\hline $\begin{array}{c}\text { S. Amylase } \\
(\mathrm{IU} / \mathrm{L})\end{array}$ & $\begin{array}{c}\text { P. F. Amylase } \\
\text { (IU/L) }\end{array}$ & $\begin{array}{c}\text { No. of } \\
\text { Cases }\end{array}$ & $\begin{array}{c}\text { Average } \\
\text { Size }\end{array}$ & Duration & $\begin{array}{c}\text { Amount of } \\
\text { Spillage }\end{array}$ \\
\hline$<100 \mathrm{IU} / \mathrm{L}$ & $500 \mathrm{IU} / \mathrm{L}$ & 11 & $5 \mathrm{MM}$ & $11 \mathrm{HRS}$ & $240 \mathrm{ML}$ \\
\hline $100-200 \mathrm{IU} / \mathrm{L}$ & $1595 \mathrm{IU} / \mathrm{L}$ & 6 & $4.8 \mathrm{MM}$ & $18 \mathrm{HRS}$ & $866 \mathrm{ML}$ \\
\hline $200-300 \mathrm{IU} / \mathrm{L}$ & $2862 \mathrm{IU} / \mathrm{L}$ & 7 & $6.28 \mathrm{MM}$ & $18 \mathrm{HRS}$ & $1.5 \mathrm{LITRE}$ \\
\hline$>300 \mathrm{IU} / \mathrm{L}$ & $7287 \mathrm{IU} / \mathrm{L}$ & 6 & $12 \mathrm{MM}$ & $23 \mathrm{HRS}$ & $2.3 \mathrm{LITRE}$ \\
\hline Table 3. Correlation of Serum Amylase with Size of Perforation, Duration \\
of Perforation and Amount of Spillage in the Peritoneal Cavity
\end{tabular}

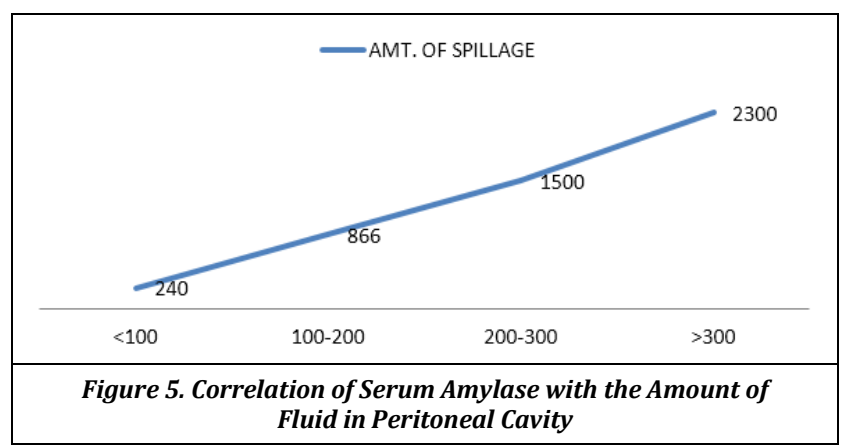

In our study we found as the amount of spillage increases the serum amylase and peritoneal fluid level amylase also increases as shown by the graph.

\begin{tabular}{|c|c|c|c|c|}
\hline S. Amylase & No. of Cases & Shock & Complications & Mortality \\
\hline Less than 100 IU/L & 11 & 0 & 0 & 0 \\
\hline $100-200 \mathrm{IU} / \mathrm{L}$ & 6 & 1 & 2 & 0 \\
\hline $200-300 \mathrm{IU} / \mathrm{L}$ & 7 & 1 & 2 & 0 \\
\hline$>300 \mathrm{IU} / \mathrm{L}$ & 6 & 4 & 5 & 1 \\
\hline Table 4. Correlation of Serum Amylase with Complications \\
of Perforation \\
\hline
\end{tabular}


With raising amylase level, the haemodynamic instability increases, post-op complications increase. In our study 11 cases had serum amylase levels less than 100 and were haemodynamically stable pre, intra and post op period and recovered uneventfully. As compared to cases who had serum amylase levels more than 300 were 6,4 came in shock and 5 had complications and 1 mortality was noted.

\begin{tabular}{|c|c|}
\hline Complication & No. of Cases \\
\hline Sepsis & 6 \\
\hline Wound infection & 2 \\
\hline Pleural effusion & 4 \\
\hline Bronchopneumonia & 1 \\
\hline MODS \& ARDS & 1 \\
\hline \multicolumn{2}{|c|}{ Table 5. Post-Op Complications } \\
\hline
\end{tabular}

Most of the patients that is 6 developed post-op sepsis. Second common complication was Pulmonary complications were noted in 6 cases. There was a significant direct correlation between serum amylase levels and duration of perforation $(\mathrm{r}=0.41, \mathrm{p}=0.03)$, size of perforation $(\mathrm{r}=0.4$, $\mathrm{p}=0.03)$ and amount of spillage perforation $(\mathrm{r}=0.66$, $\mathrm{p}<0.001$ ). There was no significant correlation between duration of perforation and size of perforation with amount of spillage.

\begin{tabular}{|c|c|c|c|c|}
\hline & & $\begin{array}{c}\text { Duration of } \\
\text { Perforation } \\
\text { (in Hrs.) }\end{array}$ & $\begin{array}{l}\text { Size } \\
\text { (in } \\
\text { mm) }\end{array}$ & \begin{tabular}{|c} 
Amount of \\
Spillage \\
(in Litres)
\end{tabular} \\
\hline \multirow{3}{*}{ Serum Amylase $>60$} & Pearson Correlation & .407 & .400 & .660 \\
\hline & Sig. (2-tailed) & .026 & .028 & .000 \\
\hline & $\mathrm{N}$ & 30 & 30 & 30 \\
\hline \multirow{3}{*}{$\begin{array}{l}\text { Duration of } \\
\text { Perforation (in Hrs.) }\end{array}$} & Pearson Correlation & & .328 & .244 \\
\hline & Sig. (2-tailed) & & .076 & .194 \\
\hline & $\mathrm{N}$ & & 30 & 30 \\
\hline \multirow{3}{*}{ Size (in mm) } & Pearson Correlation & & & .305 \\
\hline & Sig. (2-tailed) & & & .101 \\
\hline & $\mathrm{N}$ & & & 30 \\
\hline \multicolumn{5}{|c|}{$\begin{array}{l}\text { Table 6. Bivariate Relationship between Serum Amylase with } \\
\text { Duration of Perforation, Size of Perforation and Amount of Spillage }\end{array}$} \\
\hline
\end{tabular}

There was a significant positive correlation of serum amylase with all clinical biomarkers such as blood urea $(\mathrm{r}=0.77, \mathrm{p}<0.001)$, serum creatinine $(\mathrm{r}=0.88 \mathrm{p}<0.001)$, $\operatorname{INR}(\mathrm{r}=0.88 \mathrm{p}<0.001)$. There was a significant inverse correlation between serum amylase levels with Total counts $(\mathrm{r}=-0.55, \mathrm{p}=0.001$ and platelet $\operatorname{counts}(\mathrm{r}=-0.43, \mathrm{p}=0.02)$. Peritoneal fluid amylase also correlated positively and significantly with blood urea, $r=0.68, \mathrm{p}<0.001)$, serum creatinine ( $\mathrm{r}=0.68 \mathrm{p}<0.001)$, INR $(\mathrm{r}=0.84 \mathrm{p}<0.001)$, Tachycardia $(\mathrm{r}=0.76, \mathrm{p}<0.001)$. There was a significant inverse correlation between Peritoneal fluid amylase levels with Total counts $(\mathrm{r}=-0.48, \mathrm{p}=0.007$ and platelet counts $(\mathrm{r}=-0.50, \mathrm{p}=0.005)$.

\section{DISCUSSION}

Hollow viscus perforation is a common surgical emergency. According to Musgrove et al [4] elevated serum amylase and peptic ulcer perforations, noted a direct relationship between the size of the perforation, the degree of peritoneal soilage and the serum amylase. Of interest is a comparison of the significantly increased mortality rate of 32 per cent for the cases with high serum amylase, and the over-all mortality of 10.6 per cent cases with essentially normal levels. This fatality rate increases roughly three times as the amylase levels go higher. According to Lunevicius R, Morkevicius $\mathrm{M}$ et al current peak age is 40-60 years.[6] In our study peak incidence was noted in elderly age group that is $50-70 \mathrm{yrs}$. In our study male to female is 14:1. According to Lagoo $\mathrm{S}$ et al[7] $29 \%$ patients have a history of peptic ulcer disease. In our study $60 \%$ of cases had history of APD. According to Zittel TT and Jehle EC et al[8] the perforation site usually involves the anterior wall of the duodenum (60\%). In our study $70 \%$ cases had perforation in D1. In our study $16 \%$ mortality was noted in cases with elevated amylase levels compared to $0 \%$ mortality with normal group. In perforations between 16 and 24 hours old, one half of the cases had large or massive amounts of peritoneal fluid. It indicates that for cases of gastroduodenal perforation, the mortality rises as the amount of abdominal fluid increases.

Frank A. Rogers et al reported that among patients with perforated ulcers and elevated serum amylase levels, the higher the amylase level, the higher the mortality rate. $\mathrm{He}$ also concluded that the amount of abdominal fluid spill, the duration of the perforation before surgical closure, the size of the perforation, shock and recent ingestion of food were also having relationship with elevated serum amylase. All appeared to be statistical if not etiological associates of abnormal serum amylase levels. High amylase titers and large and massive amounts of abdominal fluid were statistically companion-ate. In our study there was a significant direct correlation between serum amylase levels and duration of perforation $(r=0.41, p=0.03)$, size of perforation $(r=0.4$, $\mathrm{p}=0.03)$ and amount of spillage perforation $(\mathrm{r}=0.66$, $\mathrm{p}<0.001)$.All of these factors are responsible for the outcome of the patient and affect morbidity and mortality.There was a significant positive correlation of serum amylase with all clinical biomarkers such as blood urea $(r=0.77, p<0.001)$, serum creatinine $(r=0.88 \mathrm{p}<0.001)$,, INR( $\mathrm{r}=0.88 \mathrm{p}<0.001)$,, Tachycardia( $\mathrm{r}=0.91, \mathrm{p}<0.001)$, and peritoneal fluid amylase levels $(\mathrm{r}=0.80, \mathrm{p}<0.001)$. There was a significant inverse correlation between serum amylase levels with Total counts $(\mathrm{r}=-0.55, \mathrm{p}=0.001$ and platelet $\operatorname{counts}(\mathrm{r}=-0.43, \mathrm{p}=0.02)$. Peritoneal fluid amylase also correlated positively and significantly with blood urea, $r=0.68, p<0.001$ ), serum creatinine $(\mathrm{r}=0.68 \mathrm{p}<0.001), \quad$ INR $\quad(\mathrm{r}=0.84 \mathrm{p}<0.001)$, Tachycardia $(r=0.76, p<0.001)$. There was a significant inverse correlation between Peritoneal fluid amylase levels with Total counts( $\mathrm{r}=-0.48, \mathrm{p}=0.007$ and platelet counts $(\mathrm{r}=-0.50, \mathrm{p}=0.005)$.

Lau W Y et al[9] reported most common complications being pulmonary complications in 3.6-30\%. In our study $42.8 \%$ cases developed pulmonary complications like pleural effusion, pneumonia and ARDS.

\section{CONCLUSIONS}

Peptic ulcer perforation peak incidence was noted in age group 60-70 yrs. Most of the patients affected were males (93\%); ratio being 14:1. Smoking and acid peptic disease are risk factors. Mortality in our study was $3 \%$. Size, duration and amount of fluid in peritoneal cavity correlate positively with increased morbidity and mortality. Size, duration and amount of fluid in peritoneal cavity correlate positively with 
increased serum amylase and peritoneal fluid amylase Increased amylase level can be used as a prognostic indication in peptic ulcer perforation. Prompt diagnosis and early treatment are essential for better outcome of patients. Pulmonary complications were most commonly seen compliactions in this study.

\section{REFERENCES}

[1] Mann CV, Russel RCG, Williams NS. Bailey \& Love's Short practice of surgery. 26 $6^{\text {th }}$ edn. Chapman \& Hall 1995.

[2] Chalya PL, Mabula JB, Koy M, et al. Clinical profile and outcome of surgical treatment of perforated peptic ulcers in Northwestern Tanzania: a tertiary hospital experience. World J Emerg Surg 2011;6:31.

[3] Di Saverio S, Bassi M, Smerieri N, et al. Diagnosis and treatment of perforated or bleeding peptic ulcers: 2013 WSES position paper. World J Emerg Surg 2014;9:45.
[4] Musgrove JE. Elevated serum amylase levels associated with perforated gastroduodenal lesions. Proc Staff Meet Mayo Clin 1950;25(1):8-10.

[5] Rogers FA. Serum amylase in peptic gastroduodenal perforation. A study to determine the significance of abnormally high levels. California Medicine 1960;93:610.

[6] Lunevicius R, Morkevicius M. Perforated duodenal ulcer: benefits and risks of laparoscopic repair. Medicina (Kaunas) 2004;40(6):522-37.

[7] Lagoo S, McMahon RL, Kakihara M, et al. The sixth decision regarding perforated duodenal ulcer. JSLS 2002;6(4):359-68.

[8] Zittel TT, Jehle EC, Becker HD. Surgical management of peptic ulcer disease today--indication, technique and outcome. Langenbecks Arch Surg 2000;385(2):84-96.

[9] Lau WY, Leung KL, Kwong KH, et al. A randomized study comparing laparoscopic versus open repair of perforated peptic ulcer using suture or sutureless technique. Ann Surg 1996;224(2):131-8. 